\title{
Desenvolvimento inicial de combinações de enxertos de laranjeiras doces sobre porta- enxertos de citrandarin e tangerineira
}

\author{
Initial development of combinations of sweet orange grafts on citrandarin and tangerineira graft \\ holders
}

Desarrollo inicial de combinaciones de injertos de naranja dulce sobre portainjeros de citrandarina y tangerineira

\author{
Nágila Sabrina Guedes da Silva \\ ORCID: https://orcid.org/0000-0003-4006-1652 \\ Universidade Federal Rural de Pernambuco, Brasil \\ E-mail: nagilasabrinaguedes@gmail.com \\ Rhaiana Oliveira de Aviz \\ ORCID: https://orcid.org/0000-0002-4462-4339 \\ Universidade Federal Rural de Pernambuco, Brasil \\ E-mail: rhaianaoliveiradeaviz@gmail.com@gmail.com \\ Pablo Henrique de Almeida Oliveira \\ ORCID: https://orcid.org/0000-0001-9128-6179 \\ Universidade Federal Rural de Pernambuco, Brasil \\ E-mail: pabloalmeidaagro@gmail.com \\ Ana Flavia Trindade de Lima \\ ORCID: https://orcid.org/0000-0003-3246-9412 \\ Universidade Federal Rural de Pernambuco, Brasil \\ E-mail: flahtrindadelima@gmail.com \\ Simone Andrea dos Santos Nascimento Batista \\ ORCID: https://orcid.org/0000-0002-3316-6264 \\ Universidade Federal Rural de Pernambuco, Brasil \\ E-mail: simoneandre28@gmail.com \\ Fabio Costa Esteves Junior \\ ORCID: https://orcid.org/0000-0001-8874-8547 \\ Universidade Federal Rural da Amazônia, Brasil \\ E-mail: fabioesteves1408@gmail.com \\ Paulo Guilherme Leão Gomes \\ ORCID: https://orcid.org/0000-0001-9449-9567 \\ Universidade Federal Rural da Amazônia, Brasil \\ E-mail: leaosin88@gmail.com \\ Paulinha Souza dos Santos \\ ORCID: https://orcid.org/0000-0002-0628-4230 \\ Universidade Federal Rural da Amazônia, Brasil \\ E-mail: parlysouza20@gmail.com \\ Evaristo Jorge Oliveira de Souza \\ ORCID: https://orcid.org/0000-0002-2206-414X \\ Universidade Federal Rural de Pernambuco, Brasil \\ E-mail: evaristojorge@gmail.com
}

\begin{abstract}
Resumo
Na citricultura, a diversificação da combinação de copas e porta-enxertos é uma necessidade para obter sucesso no pegamento do enxerto, diminuir o tempo de estabelecimento da planta no campo e melhorar o potencial produtivo. Dessa forma, esse trabalho tem como objetivo avaliar o desenvolvimento inicial de combinações de copas de laranjeiras doces ('Pera D6', Pera rio e Natal) com porta-enxertos de citrandarin (San Diego) e tangerineira (Sunki tropical). O experimento foi realizado em casa de vegetação pertencente a Fazenda Lima, localizada no município de Capitão Poço, Estado do Pará. Foi utilizado delineamento inteiramente casualizado, arranjados em esquema fatorial 2x3, sendo um porta-enxerto de citrandarin (San Diego) e um de tangerineira (Sunki tropical) e três copas de cultivares de laranjas doce ('Pera D6', Pera rio e Natal). A técnica utilizada foi a borbulhia por T-invertido. Após 12 dias da realização da enxertia foi removida a fita de enxerto e com 26 dias após a enxertia foram coletadas as variáveis altura do enxerto, diâmetro do caule dos enxertos e quantidade de folhas do enxerto. Os dados obtidos foram sujeitos ao teste de normalidade de Shapiro-Wilk e análise de variância, as médias foram comparadas pelo teste de Scott-Knott 5\%, com o auxílio do
\end{abstract}


software ASSISTAT. A combinação entre laranjeira 'Pera D6' e tangerineira Sunki tropical apresentou melhor desenvolvimento inicial.

Palavras-chave: Produção de mudas; Citricultura; Enxertia.

\begin{abstract}
In citriculture, diversification of the combination of crowns and rootstocks is a necessity to obtain success in graft taking, to decrease the time of establishment of the plant in the field and to improve the productive potential. Thus, this work aims to evaluate the initial development of combinations of sweet orange tree tops ('Pera D6', Pera rio and Natal) with citrandarin (San Diego) and mandarin (Sunki tropical) rootstocks. The experiment was carried out in a greenhouse belonging to Fazenda Lima, located in the municipality of Capitão Poço, State of Pará. A completely randomized design was used, arranged in a $2 \times 3$ factorial scheme, being a citrandarin rootstock (San Diego) and one of mandarin (Sunki tropical) and three cups of sweet orange cultivars ('Pera D6', Pera rio and Natal). The technique used was inverted Tbubbling. After 12 days of the grafting, the graft tape was removed and with 26 days after the grafting, the variables height of the graft, stem diameter of the grafts and quantity of graft leaves were collected. The data obtained were subjected to the Shapiro-Wilk normality test and analysis of variance, the means were compared using the Scott-Knott $5 \%$ test, with the assistance of the ASSISTAT software. The combination of 'Pera D6' orange and tropical Sunki mandarin showed the best initial development.
\end{abstract}

Keywords: Seedling production; Citriculture; Grafting.

\title{
Resumen
}

En citricultura, la diversificación de la combinación de coronas y portainjertos es una necesidad para obtener éxito en la toma de injertos, disminuir el tiempo de establecimiento de la planta en el campo y mejorar el potencial productivo. Así, este trabajo tiene como objetivo evaluar el desarrollo inicial de combinaciones de copas de naranjo dulce ('Pera D6', Pera rio y Natal) con portainjertos de citrandarina (San Diego) y mandarina (Sunki tropical). El experimento se llevó a cabo en un invernadero de la Fazenda Lima, ubicado en el municipio de Capitão Poço, Estado de Pará, se utilizó un diseño completamente al azar, dispuesto en un esquema factorial $2 \times 3$, siendo un patrón de citrandarino (San Diego) y uno de mandarina (Sunki tropical) y tres tazas de cultivares de naranja dulce ('Pera D6', Pera rio y Natal). La técnica utilizada fue el burbujeo en T invertido. A los 12 días del injerto se retiró la cinta del injerto y a los 26 días del injerto se recogieron las variables altura del injerto, diámetro del tallo de los injertos y cantidad de hojas del injerto. Los datos obtenidos se sometieron a la prueba de normalidad de Shapiro-Wilk y análisis de varianza, las medias se compararon mediante la prueba de Scott-Knott al 5\%, con la ayuda del software ASSISTAT. La combinación de naranja 'Pera D6' y mandarina tropical Sunki mostró el mejor desarrollo inicial.

Palabras clave: Producción de plántulas; Citricultura; Injerto.

\section{Introdução}

O Brasil é considerado um dos maiores produtores de citrus do mundo, sendo responsável por 33\% da produção mundial, equivalente a 49,40 milhões de toneladas (FAO, 2015) além da metade do suco que é produzido mundialmente (CITRUSBR, 2015). No Estado do Pará a citricultura é uma das atividades agrícolas que possui destaque e importância econômica, pois a produção abastece tanto a demanda interna quanto a demanda de outros Estados como Sergipe, São Paulo Maranhão, Piauí, Ceará, Amazonas e Amapá, além de exportar citros para o mercado Europeu (FAEPA, 2021). Em 2017 o Pará recebeu mais um destaque na citricultura, sendo primeiro Estado à receber pelo Ministério da Agricultura Pecuária e Abastecimento (MAPA) o título de "Área livre de cancro cítrico" através das Resoluções no 1 e 6 de março de 2017 (ADEPARÁ, 2017). Nesse sentido, a demanda produtiva de citros tem crescido nos últimos anos, sendo necessário a busca por melhores combinações de enxerto/ porta enxerto com maior potencial produtivo.

A produção de mudas é uma fase crucial na produção de citros, pois a qualidade da muda pode interferir na produtividade da cultura, que será observada somente anos depois do estabelecimento da planta no campo. Dentre as técnicas de propagação utilizadas na citricultura a enxertia é a predominante, pois através dela é possível ter maior rapidez no estabelecimento da planta, utilizar porta-enxertos mais resistentes e com tolerância à estresses bióticos e abióticos presentes no solo, multiplicar clones produtivos que possuem problemas de enraizamento, entre outras possibilidades (Efrom \& Souza, 2018).

Entretanto, para obter sucesso na enxertia entre cultivares ou espécies de citros, é necessário possuam compatibilidade morfológica e fisiológica. Dessa forma, são escolhidas plantas que pertencem à mesma família ou gênero, de acordo com a 
classificação botânica (Ribeiro et al., 2005). Além disso, o porta-enxerto também influencia na produtividade e qualidades dos frutos, e de acordo com Graça et al. (2015) os porta-enxertos que apresentam maior produtividade são limão Cravo e Volkameriano, tangerinas Sunki e Kinnow, citrumelo Swingle e citrange Morton.

No Estado do Pará predomina o uso do limoeiro cravo como porta-enxerto e laranjeira 'Pera' como copa no cultivo citrícola, entretanto é necessário buscar novas combinações de porta-enxerto e copa que possuam afinidade, sucesso no pegamento e rápido desenvolvimento vegetativo, e que também tenham potencial para aumentar a produção e diversificar o cultivo de citros no Estado (Ferreira, 2019). Dessa forma, o objetivo do estudo foi avaliar o desenvolvimento inicial de combinações de copas de laranjeiras doces [Citrus sinensis (L.) Osbeck] ('Pera D6', Pera rio e Natal) com porta-enxertos de citrandarin San Diego (C. sunki x P. trifoliata Swingle) e tangerineira Sunki tropical (C. sunki Hort. ex Tan.).

\section{Metodologia}

O experimento foi realizado na Fazenda Lima em casa de vegetação coberta com filme plástico anti-UV transparente com $150 \mu \mathrm{m}$ de espessura, fechada lateralmente com tela sombrite. A área está localizada no município de Capitão Poço, região nordeste do Estado do Pará. O Rio Guamá é o principal rio de Capitão Poço, sendo um limite geográfico entre os municípios de Capitão Poço e Ourém (PDDU, 2006; PMGIRS, 2014; Bezerra \& Sousa, 2019). Segundo classificação de Köppen, o município de Capitão Poço apresenta um clima classificado como Am, descrito como chuvoso, exibindo uma estação seca entre os meses de setembro e novembro. A temperatura média anual é de $26,2^{\circ} \mathrm{C}$. A precipitação pluviométrica é de $2.401 \mathrm{~mm}$ anuais e, com uma umidade relativa em aproximadamente 83\% (Pacheco \& Bastos, 2001; Santos et al., 2015; Rodrigues, 2016).

O experimento foi realizado em delineamento inteiramente casualizado, arranjados em esquema fatorial 2x3, sendo um porta-enxertos de citrandarin (San Diego) e um de tangerineira (Sunki tropical) e três copas de cultivares de laranjas doce ('Pera

D6', Pera rio e Natal), com 5 repetições. Os porta-enxertos são híbridos de citros e provenientes de sementes certificadas. As copas enxertadas foram provenientes da fazenda. Os tratamentos são os seguintes: T1: 'Pera D6' x Sunki Tropical, T2: Pera Rio x Sunki Tropical, T3: Natal x Sunki Tropical, T4: ‘Pera D6’ x San Diego, T5: Pera Rio x San Diego e T6: Natal x San Diego.

Os porta-enxertos foram semeados em tubetes de $75 \mathrm{ml}$, preenchidos com substrato de fibra de coco. As bandejas dos tubetes foram dispostas em bancadas de concreto, com altura de $40 \mathrm{~cm}$ do solo. Sete dias após a germinação, os porta-enxertos foram submetidos a fertirrigação de três a cinco vezes por semana. A irrigação foi realizada manualmente e sempre que necessário, levando-se em consideração a umidade do substrato. A cada 15 dias era realizado o controle preventivo de doenças com o uso de fungicidas cúpricos, através de pulverização. Para o controle de pragas como cochonilhas, ácaros e larva-minadora foi utilizado abamectina e metidationa, conforme observações no viveiro.

Os porta-enxertos foram transplantados após 45 dias do semeio, para sacos plásticos com capacidade de 5 litros e preenchidos com fibra de coco. Foram conduzidos em haste única, retirando as brotações laterais semanalmente. Três meses após o semeio, foi realizado a enxertia quando os porta-enxertos atingiram diâmetro de 5 à $6 \mathrm{~mm}$ e $14 \mathrm{~cm}$ acima do colo da planta. A técnica utilizada foi a borbulhia por T-invertido, realizando o forçamento da enxertia pelo encurvamento do portaenxerto para fora das bancadas. As borbulhias utilizadas foram coletadas de plantas matrizes indexadas da própria fazenda que logo foram destinadas imediatamente à enxertia. Foi utilizado fita para fixar as copas em seus respectivos porta-enxertos. Após 12 dias da realização da enxertia a fita foi removida do enxerto. Com 26 dias da realização da enxertia, foram coletadas as variáveis de altura total do enxerto utilizando uma fita métrica, diâmetro do caule dos enxertos usando um paquímetro digital e quantidade de folhas do enxerto.

Os dados obtidos foram inicialmente sujeitos ao teste de normalidade de Shapiro-Wilk e, posteriormente, foram submetidos à análise de variância e ao teste de comparação de médias de Scott-Knott 5\%, com o auxílio do software ASSISTAT (Silva \& Azevedo, 2016). Para a geração dos gráficos foi utilizado o software Excel. 


\section{Resultados e Discussão}

O teste de Shapiro-Wilk mostrou que todos os dados apresentaram normalidade, e de acordo com a análise de variância, apresentada na Tabela 1, para fator copa (A) verificou-se efeito significativos somente para as características número de folhas do enxerto e altura do enxerto. Para fator porta-enxerto (B), ocorreu efeito significativo para a característica número de folha do enxerto, demonstrando que essa variável pode ser influenciada pelo porta-enxerto. Para o fator interação (AxB) verificou-se efeito significativo para a característica altura do enxerto. Em relação ao efeito não significativo, a variável diâmetro do enxerto não demonstrou significância para os três fatores (A, B e AxB).

Tabela 1 - Resumo da análise de variância das variáveis diâmetro, número de folhas e altura do enxerto de combinações de copas de laranjeiras doces com porta-enxertos de citrandarin e tangerineira.

\begin{tabular}{ccccc}
\hline Variáveis & Fator & G.L. & $\mathrm{F}$ & $\mathrm{P}$ \\
\hline \multirow{2}{*}{ Diâmetro do } & Copa (A) & 2 & $3.2444 \mathrm{~ns}$ & 0.0566 \\
enxerto & Porta-enxerto (B) & 1 & $2.2080 \mathrm{~ns}$ & 0.1502 \\
& Interação (AxB) & 2 & $0.4952 \mathrm{~ns}$ & 0.6155 \\
\hline Número de & Copa (A) & 2 & $4.7951 *$ & 0.0177 \\
folhas do & Porta-enxerto (B) & 1 & $14.0852 * *$ & 0.0006 \\
enxerto & Interação (AxB) & 2 & $0.8134 \mathrm{~ns}$ & 0.4552 \\
\hline \multirow{2}{*}{ Altura do } & Copa (A) & 2 & $16.7805 * *$ & 0.0004 \\
enxerto & Porta-enxerto (B) & 1 & $1.6405 \mathrm{~ns}$ & 0.2123 \\
& Interação (AxB) & 2 & $6.7172 * *$ & 0.0048 \\
\hline
\end{tabular}

G.L.: graus de liberdade; ${ }^{* *}$ Significativo a 0,01 de probabilidade; *Significativo a 0,05 de probabilidade; ns Não significativo.

Fonte: Autores.

Para a característica número de folha do enxerto, verificou-se efeito significativos para as copas 'Pera D6' (10 folhas) e Natal ( 8 folhas), mostrando a cultivar Pera rio (6 folhas) com valor médio inferior ao número de folha das demais cultivares. (Gráfico 1).

Gráfico 1 - Número de folhas do enxerto (NFE) de copas 'Pera D6', Pera rio e Natal, cultivadas sobre porta-enxerto de citrandarin e tangerineira.

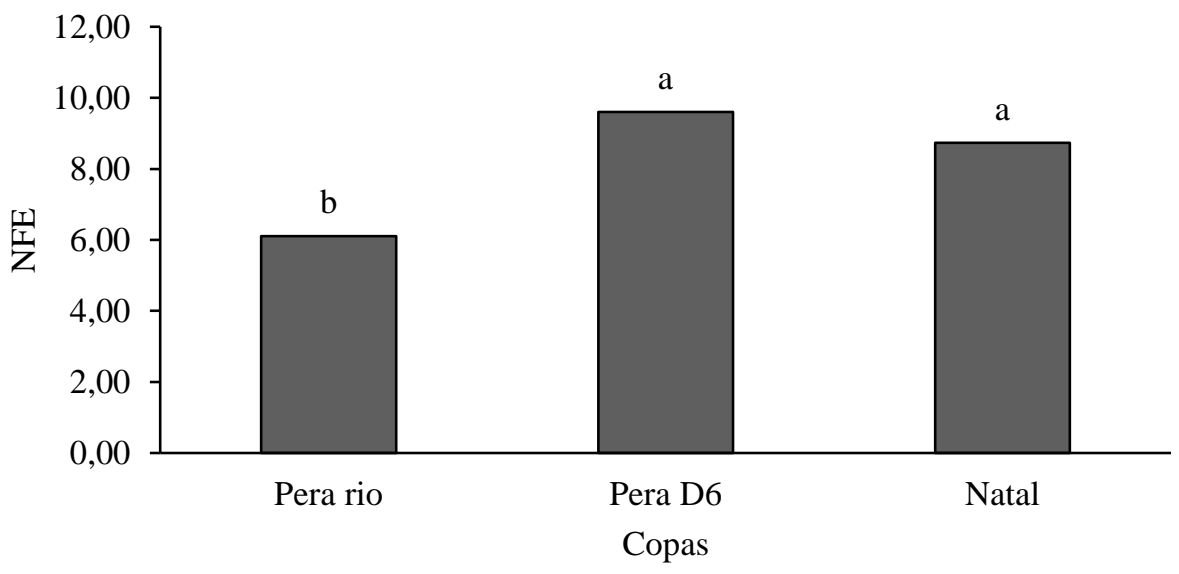

As médias seguidas pela mesma letra não diferem estatisticamente entre si pelo Teste Scott-Knott ao nível de 5\% de probabilidade; $\mathrm{CV} \%=$ 32.13.

Fonte: Autores. 
A quantidade de folhas por planta é um fator determinante para a captação da energia solar e $\mathrm{CO}_{2}$, e também produção de compostos orgânicos através da fotossíntese, sendo é o órgão que mais armazena nutrientes na planta. (Taiz et al., 2007). As características do fruto estão mais relacionadas com a copa, por sua vez, o porta enxerto possui influência direta nas características sobre a copa como, vigor, precocidade, produção, vigor, número de folhas e fruto (Bastos et al., 2014) assim, a escolha, a escolha tanto da copa como do porta enxerto são decisivos e vão determinar o desempenho da planta.

Quanto à influência do porta-enxerto sobre o número de folhas do enxerto, observou-se efeito significativo para portaenxerto Sunki Tropical (10 folhas) com valor médio superior comparado com porta-enxerto San Diego (6 folhas) (Gráfico 2).

Gráfico 2 - Número de folhas do enxerto (NFE) de copas 'Pera D6', Pera rio e Natal, cultivadas sobre porta-enxerto de citrandarin e tangerineira.

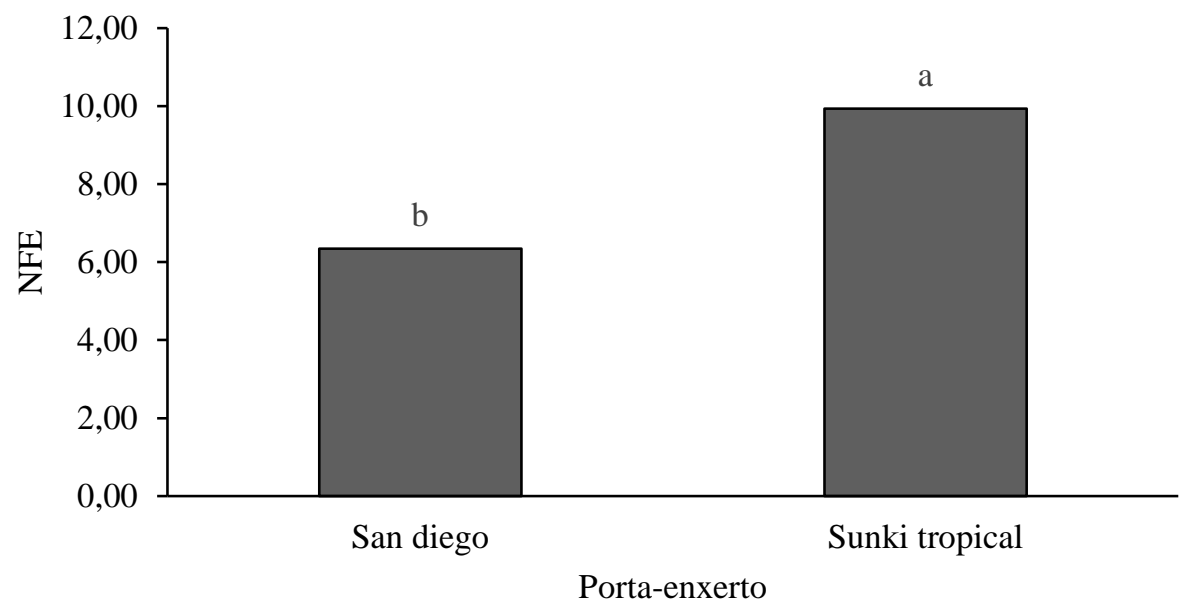

As médias seguidas pela mesma letra não diferem estatisticamente entre si pelo Teste Scott-Knott ao nível de 5\% de probabilidade; CV\% = 32.13 .

Fonte: Autores.

De acordo com valores observados, A superioridade do Sunki foi também observada por Montalvão (2020), comparando com o porta-enxerto 'Flying Dragon', no entanto, apresentou valores semelhantes aos porta-enxertos 'Cravo', Citrumelo, 'Cleópatra' e 'Gou Tou’ em relação aos caracteres avaliados. O fato do porta-enxerto San Diego apresentar menor média no número de folha, pode estar ligado à resposta da planta ao manejo realizado, pois em outros trabalhos, como os realizados por Rodrigues et al. (2018) e Sombra et al. (2019) este porta-enxerto demonstra resultado superiores de germinação e desenvolvimento que a tangerineira Sunki Tropical.

Em relação à altura do enxerto, observou-se efeito significativo para as copas 'Pera D6' $(14 \mathrm{~cm})$ e Natal (11 cm), com valores de médias superiores a cultivar Pera rio que apresentou menor valor $(6 \mathrm{~cm})$ (Gráfico 3). 
Gráfico 3 - Altura do enxerto (AE) de copas 'Pera D6', Pera rio e Natal, cultivadas sobre porta-enxerto de citrandarin e tangerineira.

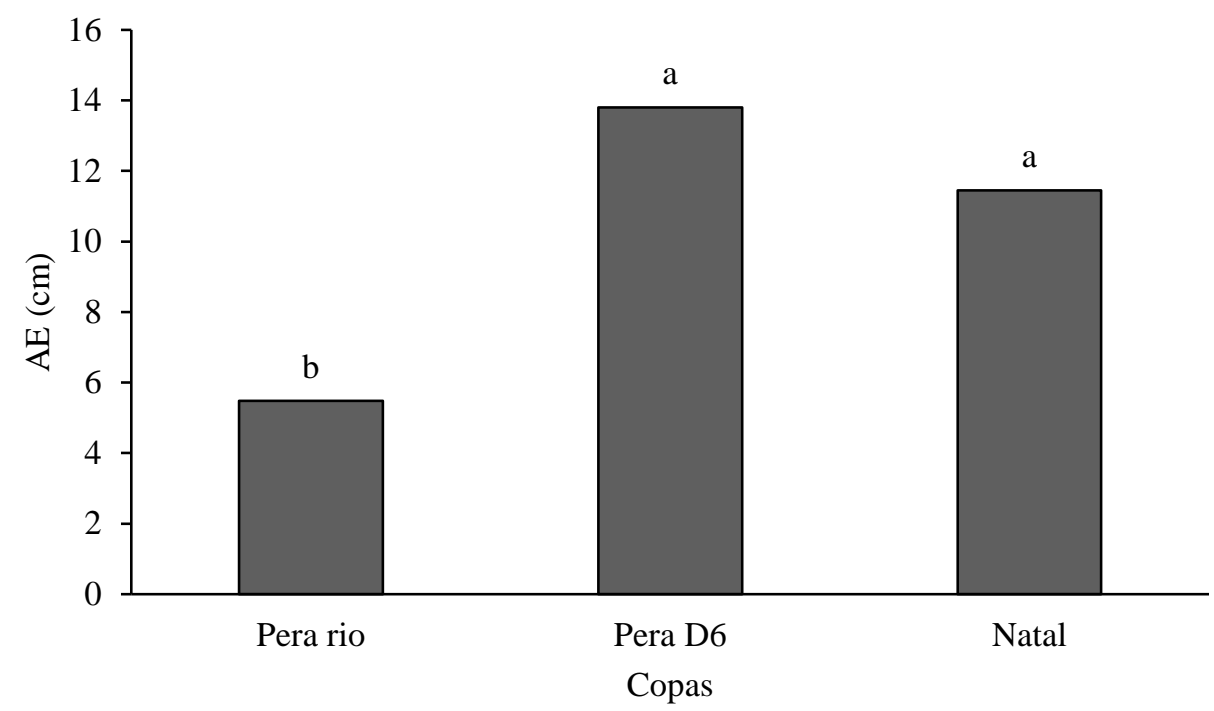

As médias seguidas pela mesma letra não diferem estatisticamente entre si pelo Teste de Scott-Knott ao nível de 5\% de probabilidade; CV\% $=32.32$.

Fonte: Autores.

De acordo com Felker et al. (2015), altura da parte aérea fornece uma excelente estimativa da predição do crescimento inicial, sendo tecnicamente aceita como uma boa medida do potencial de desempenho das mudas, além de não acarretar destruição das plantas. Dessa forma as copas 'Pera D6' e Natal apresentaram bom desenvolvimento inicial comparado a Pera rio. No trabalho de Auler et al. (2008) os autores verificaram que o porta-enxerto de tangerina 'Sunki' apresentou melhor altura na planta, no entanto, os mesmos mencionam que plantas com altura menor são melhores para uma boa manutenção, beneficiando o controle de pragas e doenças. Além disso, plantas com porte menor demonstram vantagem como aumento da densidade do plantio, na colheita, na poda, nos tratos culturais e redução nos custos de produção (Lima et al., 2014).

Gráfico 4 - Altura do enxerto (AE) de copas 'Pera D6', Pera rio e Natal combinadas com porta-enxertos San Diego e Sunki Tropical.

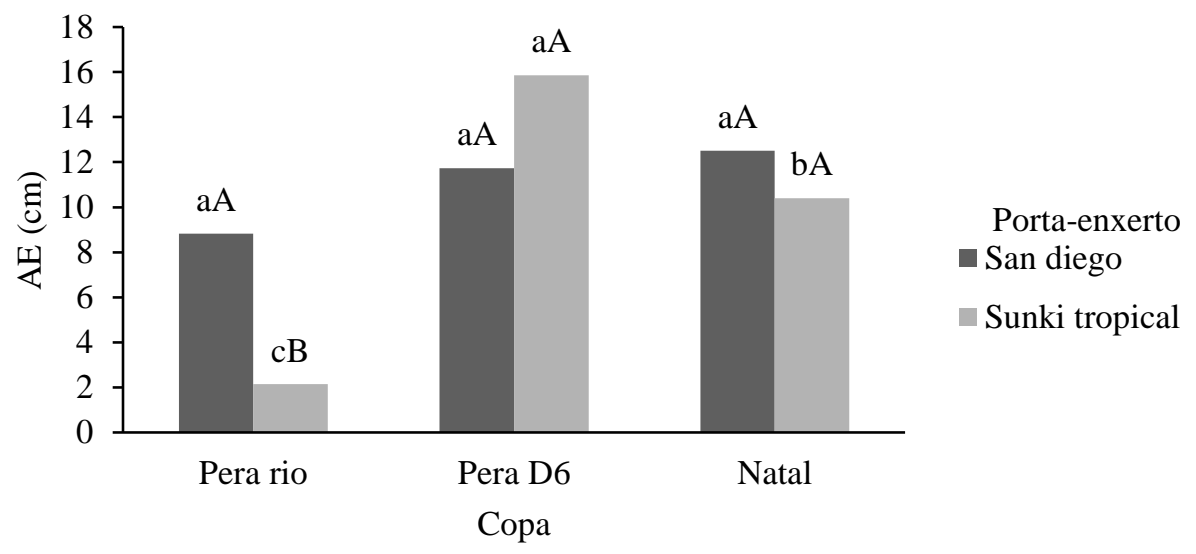

Letras minúscula copa; letra maiúscula porta-enxerto; as médias seguidas pela mesma letra não diferem estatisticamente entre si pelo o teste de Scott-Knott ao nível de $5 \%$ de probabilidade; $\mathrm{CV} \%=32$.

Fonte: Autores. 
A interação entre os fatores copa (A) e porta-enxerto (B) mostrou resposta significativa para altura do enxerto, e de acordo com os resultados (Gráfico 4) a copa pera rio apresentou resultado superior quando enxertado sobre citrandarin San Diego (9 folhas), para copa 'Pera D6' e Natal não houve diferença significativa entre os porta-enxertos, mostrando bom desenvolvimento quando enxertada tanto em San Diego (12 folhas) quanto em tangerineira Sunki tropical (10 a 16 folhas).

No trabalho de Nascimento et al. (2018) o enxerto de laranjeira 'Pera' combinado com o porta-enxerto 'Sunki' apresentou a segunda maior altura, diâmetro do coleto abaixo e acima da enxertia e volume da copa comparado com os outros porta-enxertos estudados, ficando somente atrás do porta-enxerto 'Riverside'. As copas quando enxertadas sobre citrandarin San Diego apresentaram superioridade estatística em relação a variável analisada, e isso pode ser explicado pelo fato de que o portaenxerto pode ser compatível com as copas. A copa pera rio sobre porta-enxerto Sunki Tropical apresentou resultado inferior aos demais, e isso pode ter ocorrido devido a característica do enxerto, pois a Pera rio apresentou desenvolvimento inferior as demais copas. Para as cultivares pera rio e Natal os valores médios foram menores quando cultivadas no porta-enxerto 'Sunki Tropical', e isso pode ter ocorrido devido a influência que esse porta-enxerto exerce sob a copa, mostrando baixo valor de desenvolvimento.

Entretanto, o porta-enxerto 'Sunki' favoreceu a indução da produtividade a outras variedades de laranja doce, como 'Tuxpan Valencia', 'Jaffa', 'Abacaxi' e 'Sincorá', levando-se em consideração os porta-enxertos de limão 'Cravo' e limão 'Rough' que são resistentes à seca (França et al. 2016; Teodoro et al. 2020; Carvalho et al. 2019). Para Passos e Silva (2018), o portaenxerto 'Sunki Tropical' apresentou um bom desenvolvimento nos parâmetros de altura de planta e diâmetro do caule, bem como são os melhores incrementos em mudas de laranjeira 'Pêra', no município de Capitão Poço-PA.

\section{Conclusão}

A combinação entre enxerto laranjeira 'Pera D6' e porta-enxerto tangerineira Sunki tropical apresentou melhor desenvolvimento inicial, devido a superioridade nos resultados de número de folhas, altura do enxerto e a sua interação em relação à altura, sendo essa a indicada para uso. Além disso, novos estudos poderão ser feitos para verificar a produtividade dos enxertos e porta-enxertos estudados.

\section{Referências}

ADEPARÁ - Agência de Defesa Agropecuária Do Estado Do Pará. (2017). Decreto do Governo do Estado cria dois polos citrícolas no Pará. http://www.adepara.pa.gov.br/artigos/decreto-do-governo-do-estado-cria-dois-polos-citrícolas-no-pará.

Auler, P. A. M., Fiori-Tutida, A. C. G., \& Tazima, Z. H. (2008). Comportamento da laranjeira'Valência'sobre seis porta-enxertos no noroeste do Paraná. Revista Brasileira de Fruticultura, 30, 229-234.

Bastos, D. C; Ferreira, E.A; Passos, O.S. Cultivares copa e porta-enxertos para a citricultura brasileira. Jornal Informes Agropecuários, $34-45$ 35, ano 2014.

Bezerra, G. D. D. C. \& Sousa, M. S. D. (2019). Classificação do uso e cobertura da terra da sub-bacia do Rio Indua - Capitão Poço - Pa [Trabalho de Conclusão de Curso (Graduação em Agronomia) - Universidade Federal Rural da Amazônia, Capitão Poço].

Carvalho, L. M., Carvalho, H. W. L., Barros, I., Martins, C. R., Soares Filho, W. S., Girardi, E. A., \& Passos, O. S. (2019). New scion-rootstock combinations for diversification of sweet orange orchards in tropical hardsetting soils. Scientia Horticulturae, 243, 169-176. https://doi.org/10.1016/j.scienta.2018.07.032

CitrusBR - Associação Nacional dos Exportadores de Sucos Cítricos. Disponível em www.citrusbr.com. Acessado em 17/02/2015.

Efrom, C. F. S., \& Souza, P. V. D. (2018). Citricultura do Rio Grande do Sul: indicações técnicas. SEAPI.

FAEPA - Federação Da Agricultura e Pecuária. (2021). Pará será o maior polo de Citricultura do mundo. http://sistemafaepa.com.br/am azoniarural/2019/06/10/para-sera-o-maior-polo-de-citricultura-do-mundo/\#: :text=Nacionalmente\%2C os citricultores são homenageados,produzem laranja\%2C lim ão e tangerina.

Felker, R. M., Aimi, S. C., Stefanello, M. de M., Piazza, E. M., \& Jung, P. H. (2015). Crescimento de mudas de açoita-cavalo (Luehea divaricata Mart.) sob influência de diferentes substratos e recipientes, em viveiro. Enciclopédia Biosfera, 11(22), 809-823. https://doi.org/10.18677/enciclopedia_biosfera_2015_120

Ferreira, I. V. L. (2019). Análise do mercado da laranja (Citrus sinensis L. Osbeck) no Estado do Pará [Trabalho de Conclusão de Curso (Graduação em Agronomia) - Universidade Federal Rural da Amazônia, Belém]. http://scioteca.caf.com/bitstream/handle/123456789/1091/RED2017-Eng8ene.pdf?sequence=12\&isAllowed=y\%0Ahttp://dx.doi.org/10.1016/j.regsciurbeco.2008.06.005\%0Ahttps://www.researchgate.net/publication/305320484_SIS TEM_PEMBETUNGAN_TERPUSAT_STRATEGI_MELESTARI. 
Food and Agriculture Organization of the United Nations (FAO) (2015) Disponível em www.fao.org.br. Acessado em 20/09/2021.

França, N. O., Amorim, M. S., Girardi, E. A., Passos, O. S., \& Soares Filho, W. S. (2016). Performance of 'Tuxpan Valencia' Sweet Orange Grafted Onto 14 Rootstocks in Northern Bahia, Brazil. Revista Brasileira de Fruticultura, 38, e-684. https://doi.org/10.1590/0100-29452016684.

Graça, J., Barros, J. C. da S. M. de, Vieira, A., Filho, L. de M. R., \& Ide, C. D. (2015). A importância da diversificação do porta-enxerto para a citricultura. Pesagro-Rio. (44), 2. ISSN: 1983-6015.

Lima, C. F., Marinho, C. S., Costa, E. S., Amaral, C. O. (2014) Qualidade dos frutos e eficiência produtiva da laranjeira 'Lima'enxertada sobre 'Trifoliata', em cultivo irrigado. Revista Brasileira de Ciências Agrárias, v.9, n. 3. p. 401-405.

Montalvão, P. C. (2020). Tangerineira 'Dekopon'sobre Diferentes Porta-Enxertos [Trabalho de Conclusão de Curso (Graduação em Agronomia) - Centro Universitário de Anápolis - UniEVANGÉLICA.

Nascimento, J. S., Ferreira, P. D. S., Santo, H. C. A., \& Gurgel, F. D. L. (2018). Parâmetros morfológicos de pomar de laranjeira'pera'em combinação com diferentes porta-enxertos no município de Capitão Poço-PA. In Embrapa Amazônia Oriental-Artigo em anais de congresso (ALICE). In: SEMINÁRIO DE INICIAÇÃO CIENTÍFICA DA EMBRAPA AMAZÔNIA ORIENTAL, 22., 2018, Belém, PA. Anais... Belém, PA: Embrapa Amazônia Oriental, 2018.

Pacheco, N. A., Bastos, T. X. Caracterização climática do Município de Capitão Poço - PA. Embrapa Amazônia Oriental, Documentos, n.79, 20 p. Belém, 2001. Disponível em: www.infoteca.cnptia.embrapa.br.

Passos, J. M. C., Silva, L. M. Desenvolvimento de um pomar de limeira ácida 'tahiti' em combinação com diferentes porta-enxertos em resposta a um programa de adubação. 2018. 51 f. Trabalho de Conclusão de Curso (Graduação em Agronomia) - Universidade Federal Rural da Amazônia, Capitão Poço.

PDDU - Plano Diretor De Desenvolvimento Urbano. Capitão Poço, PA, 2006.

PMGIRS - Plano Municipal de Gestão Integrada de Resíduos Sólidos. CapitãoPoço, PA, 2014.

Ribeiro, G. D., Costa, J. N. M., Vieira, A. H., \& Santos, M. R. A. dos. (2005). Enxertia em fruteiras. In Embrapa (Vol. 364, Issue 5). Embrapa.

Rodrigues, R. S. S. Efeitos da precipitação diária sobre vazão média do corpo hídrico na Bacia do Igarapé da Prata, Capitão Poço, Pará, Brasil. 10 Simpósio Internacional de Qualidade Ambiental, 19 a 21 de outubro de 2016.

Rodrigues, M., Andrade Neto, R., Lessa, L., Girardi, E., \& Soares Filho, W. (2018). Desempenho agronômico de lima ácida tahiti em combinação com diferentes porta-enxertos em capixaba, Acre. Enciclopédia Biosfera, 15(28), 353-363. https://doi.org/10.18677/EnciBio_2018B30.

Santos, D. B. O., Blanco, C. J. C., Pessoa, F. C. L. RUSLE PARA DETERMINAÇÃO DA TOLERÂNCIA DE PERDA DE SOLO. Biota Amazônia, 5 (4): 78 83,2015 .

Silva, F. D. A. S. \& de Azevedo, C. A. V. (2016). O Assistat Software Versão 7.7 e sua utilização na análise de dados experimentais. African Journal of Agricultural Research, 11 (39), 3733-3740.

Sombra, K. E. S., Costa e Silva, A. C., Loureiro, F. L. C., Andrade, H. M. de, Bastos, D. C., \& Uchôa, C. do N. (2019). Emergência e desenvolvimento inicial de porta-enxertos de citros no semiárido do Ceará, Brasil. Citrus Research \& Technology, 40, 1-9. https://doi.org/10.4322/crt.00162

Taiz, L., Zeiger, E., Møller, I. M., \& Murphy, A. (2007). Fisiologia e desenvolvimento Vegetal. In Artmed (6th ed.). Artmed. https://linkinghub.elsevier.com/retrieve/pii/0307441276901217.

Teodoro, A. V., Carvalho, H. W. L., Barros, I., Carvalho, L. M., Martins, C. R., Soares Filho, W. S., Girardi, E. A. \& Passos, O.S. (2020). Performance of 'Jaffa' sweet orange on different rootstocks for orchards in the Brazilian Northeast. Pesquisa Agropecuária Brasileira, 55, e01665. https://doi.org/10.1590/s16783921.pab2020.v55.01665 